\title{
AQUISIÇÃO DA LINGUAGEM ESCRITA E PROCESSOS DE EDUCAÇÃO INCLUSIVA: UMA ABORDAGEM HISTÓRICO- CULTURAL
}

\author{
ACQUISITION OF WRITTEN LANGUAGE AND INCLUSIVE EDUCATION PROCESSES: \\ A HISTORICAL-CULTURAL APPROACH \\ ADQUISICIÓN DEL LENGUAJE ESCRITO Y PROCESOS DE EDUCACIÓN INCLUSIVA: \\ UN ENFOQUE HISTÓRICO-CULTURAL
}

Cleusa Inês Ziesmann E-mail: cleusa.ziesmann@uffs.edu.br

Ana Cecilia Teixeira Gonçalves E-mail: acgteixeira@uffs.edu.br

Jeize de Fátima Batista

E-mail: jeize.batista@uffs.edu.br

\begin{abstract}
RESUMO
Este artigo objetiva desenvolver uma reflexão sobre a educação inclusiva e sua relação com o outro no processo de ensino e aprendizagem, no ensino regular. Trata-se de um estudo com revisão bibliográfica e em acervos científicos a partir de autores que refletem sobre os processos de inclusão e construção da linguagem escrita. Para isso, apresenta-se uma breve introdução sobre os estudos de Lev Vygotsky e as suas contribuições para a educação inclusiva, bem como propõem-se algumas estratégias metodológicas que podem auxiliar no desenvolvimento da linguagem escrita, de forma a considerar as diferentes formas de aprender.
\end{abstract}

PALAVRAS-CHAVE: Educação Inclusiva. Linguagem escrita. Ensino e aprendizagem.

\section{ABSTRACT}

This article aims to develop a reflection on inclusive education and its relationship with the other in the process of teaching and learning, in regular education. It is a study with bibliographic review and scientific collections from authors who reflect on the inclusion and construction processes of written language. For this, a brief introduction about Lev Vygotsky's studies and his contributions to inclusive education is presented, as well as proposing some methodological strategies that can assist in the development of written language, in order to consider the different ways of learning.

KEYWORDS: Inclusive Education. Written language. Teaching and learning.

\section{RESUMEN}

Este artículo tiene como objetivo desarrollar una reflexión sobre la educación inclusiva y su relación con el otro en el proceso de enseñanza y aprendizaje, en la educación regular. Se trata de un estudio con revisión bibliográfica y colecciones científicas de autores que reflexionan sobre los procesos de inclusión y construcción del lenguaje escrito. Para ello, se presenta una breve introducción sobre los estudios de Lev Vygotsky y sus aportes a la educación inclusiva, además de proponer algunas estrategias metodológicas que pueden ayudar en el desarrollo del lenguaje escrito, con el fin de considerar las diferentes formas de aprendizaje.

PALABRAS CLAVE: Educación Inclusiva. Lengua escrita. Enseñanza y aprendizaje. 


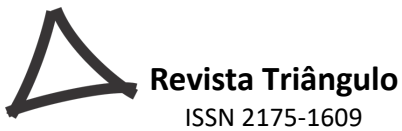

\section{INTRODUÇÃO}

Os estudos de Vygotsky estão relacionados com a Educação Especial e constituem uma fundamentação teórica no estudo da aprendizagem e do desenvolvimento da criança. Com base marxista, os seus estudos, mais especialmente o seu livro Fundamentos de Defectología Tomo V (1929), foram transformados em cinco volumes originalmente na versão russa e, mais tarde, na versão espanhola.

Conforme Bronckart (2008, pp.63-64), a teoria vygotskyana inscreve-se em uma perspectiva epistemológica que explica o desenvolvimento humano a partir de cinco pontos principais:

(a) o ser humano é dotado de um equipamento biocomportamental e psíquico inicial, que, mesmo tendo origem na evolução contínua das espécies, apresenta características novas; (b) essas novas capacidades possibilitaram a realização de atividades coletivas complexas; (c) a gestão dessas atividades demandou a emergência de um instrumento de regulação de línguas próprias aos diversos grupos; (d) a prática dos signos linguageiros, em sua relação com as atividades, permitiu a elaboração das obras e dos fatos socioculturais; (e) a apropriação e a internalização desses signos, em suas relações com as atividades e fatos sociais, gerou, paralelamente, o pensamento significante dos indivíduos.

Nesse ínterim, observa-se que a complexidade da espécie humana é o resultado de um "processo de desenvolvimento profundamente enraizado nas ligações entre história individual e história social", ou melhor, na relação entre sujeito e contexto social (VYGOTSKY, 1989, p. 36). Em vista disso, destaca-se que, em função de seu cunho sócio-histórico e interativo, a linguagem tem um relevante papel nesse processo.

Percebe-se, ainda, que é central, nas pesquisas de Vygotsky, o fato de se enfatizar a necessidade de interação com outros para efetivar o processo de ensino e de aprendizagem. Pode-se inferir, portanto, que o ser humano está em constante processo de aprendizagem e de construção de relações e que o papel do outro é central nesse percurso. Dessa forma, é dedicado ao professor o importante papel de planejar formas de ensinar para que os alunos, com ou sem deficiência, consigam interagir e estabelecer relações no ambiente escolar. A sala de aula, nessa perspectiva, é o espaço em que acontecem fenômenos sociais, pois existe ali um contexto social que influencia a socialização e o compartilhamento de experiências e conhecimentos que fazem parte do processo de aprendizagem.

No ano de 1925, Vygotsky (1997a, p. 44) deixou claro que era necessário "estudar e compreender a consciência, como sendo o tema central da nova Psicologia". Para ele, compreender a consciência é entender a forma como o comportamento humano exerce influência na sua relação com os seres vivos e com o mundo. Dessa forma, a palavra-chave dos seus estudos está na interação social, o que implica dizer que o desenvolvimento do indivíduo necessariamente se dá por meio da relação com o outro e com o mundo. Nessa mesma perspectiva, Barroco (2007, p. 200) reforça que:

Uma "psicologia sem consciência" não permite o desenvolvimento de métodos para se investigar aquilo que não é aparente ou manifesto à vista, como os movimentos 

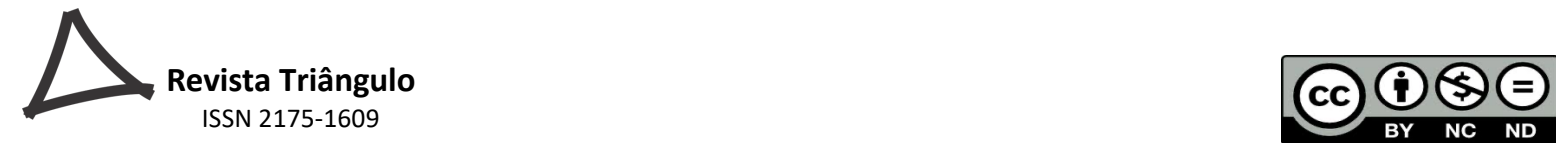

psicológicos internos, a fala interna, etc. Tal psicologia ignora que os movimentos internos, pouco conhecidos até aquele momento, dirigem e orientam o indivíduo. Quando se exclui a consciência como objeto de estudo da psicologia científica, não se expõe e não se contrapõe à psicologia dualista vigente, que separa o corpo do espírito, e que se reproduz apreendendo o homem com base em concepções reflexológicas. Por este entendimento, os processos subjetivos se tornam secundários ou epifenômenos, já que o comportamento é uma soma de reflexos.

Mesmo que Vygotsky soubesse do que estava falando em sua teoria, ele compreendia que a proposta da nova Psicologia considerava que os instintos e os impulsos faziam parte do núcleo principal da psique. De acordo com Vygotsky, Luria e Leontiev (1988, p. 25), “o homem não é apenas um produto de seu ambiente, é também um agente ativo no processo de criação deste meio" e, portanto, no seu entender, a Psicologia deveria, de fato, materializar os fatos da consciência.

Sobre esse ponto, cumpre ressaltar que, no início do século XX, havia uma tendência dentre as diferentes escolas da psicologia em subestimar e até mesmo suprimir a problemática da interação físico-psíquica. A explicação de Vygotsky para o contexto vinculava-se ao fato de que a psicologia era apoiada em uma "epistemologia dualista herdada de Descartes", segundo a qual as capacidades físicas e psíquicas do ser humano poderiam ser representadas por substâncias diferentes entre si e independentes: a substância psíquica, propriedade exclusiva da espécie humana, torna possível a existência de um "sujeito consciente" o qual tem a capacidade de regular as propriedades físicas de seu corpo (BRONCKART, 1999, p. 25). Vygotsky, posicionando-se contrariamente a essa abordagem dualista, inscrevia-se na epistemologia monista de Spinoza, a qual considera

a) que a Natureza ou o universo é constituído de uma substância única: a matéria homogênea e em perpétua atividade; b) que o físico e o psíquico são duas das múltiplas propriedades dessa substância material ativa e as únicas acessíveis à inteligência humana; c) que essa inteligência, devido a suas propriedades limitadas, não pode apreender a matéria de que se origina como uma entidade homogênea ou contínua, mas sob a forma parcial e descontínua dos fenômenos físicos e psíquicos. (BRONCKART, 1999, pp. 25-26)

Nesse sentido, ao aderir a uma epistemologia monista, Vygotsky salienta que a questão central da psicologia é investigar as condições pelas quais se deu a evolução histórica da espécie humana, isto é, analisar, de um lado, de que forma os seres humanos, durante seu processo evolutivo, desenvolveram capacidades mentais e, de outro, identificar qual é a relação dessas capacidades com o meio social em que está inserido, focalizando-se, portanto, a interação.

Pensando nesse processo interacionista defendido por Vygotsky, pode-se dialogar com o conceito de alteridade proposto por Bakhtin, que defende a necessidade do outro para constituição de sujeitos, na medida em que o ser humano concreto é inacabado e incompleto. Para Bakhtin (2003) "[...] o homem não tem um território inteiro e soberano, está todo e sempre na fronteira, olhando para dentro de si, ele olha o outro nos olhos ou com os olhos do outro" (p. 341). Ao se constituir na relação com o outro, o ser humano não se dilui nesse outro, mas se constrói a partir da interação. 


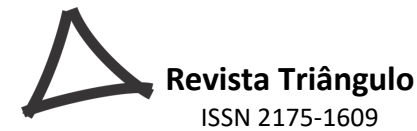

Tendo em vista a noção de interação e focalizando, sobretudo, o papel do outro no desenvolvimento humano, pode-se enfatizar, a partir das pesquisas de Elkonin (1996), que todo o trabalho de Vygotsky (1997) sempre esteve voltado para crianças, sempre realizado a partir de estudos feitos em clínicas neurológicas e psiquiátricas, e isto possibilitava a organização de materiais que contribuíam nos estudos sobre as novas formações e a compreensão do processo de sua desintegração. Conforme Elkonin (1996, p. 387),

O objetivo principal de suas investigações foi a história do surgimento, desenvolvimento e desintegração das formas superiores especificamente humanas da atividade da consciência (das suas funções). Vygotsky foi o criador do método de comunicação que denominou genético-experimental.

Esses sistemas de comunicação permitem que as crianças interiorizem a linguagem e desenvolvam as funções mentais superiores por meio de instrumentos que se tornam mediadores, podendo resultar em formas diferentes de funcionamento mental superior, promovendo a ampliação de habilidades funcionais deficitárias.

Nesse processo de interação está a construção da linguagem. Vygotsky (2002) defende que se deve entender a leitura e a escrita como um sistema simbólico equivalente à linguagem oral. Assim, torna-se necessário ajudar a criança a internalizar esse novo tipo de linguagem, e não somente ensinar-lhe a parte mecânica do processo. A criança consegue desenvolver a linguagem falada a partir do contato com outras pessoas. Entretanto, a linguagem escrita necessita de um treinamento motor para se desenvolver. Para isso, exige-se um esforço muito grande por parte do professor e do aluno, correndo-se o risco de o ensino ficar vazio, sem representações, deixando a linguagem escrita viva num segundo plano, não considerando as diferentes possibilidades de aprender.

Sendo assim, este estudo tem como objetivo desenvolver uma reflexão sobre a educação inclusiva e sua relação com o outro no processo de ensino e aprendizagem, no ensino regular. Para tanto, buscar-se-á pensar e refletir sobre o desenvolvimento do ser humano e da linguagem a partir dos estudos das obras de Vygotsky. Assim, faz-se necessário compreender o teor da sua produção no campo da Psicologia sobre o desenvolvimento humano, da Defectología, da aprendizagem e da Zona de Desenvolvimento Proximal. Dessa forma, apresentar-se-ão esses conceitos, refletindo sobre um processo de ensino inclusivo que considere as diferenças, bem como apontar-se-ão caminhos a partir de algumas propostas metodológicas para o desenvolvimento da linguagem escrita.

\section{As contribuições da teoria de Vygotsky à educação escolar inclusiva}

No período em que Vygotsky elaborou seus estudos sobre a Defectología, esta área estava relacionada a uma disciplina que estudava o desenvolvimento humano, comprometido por alguma deficiência, e analisava a formação de professores e os métodos usados para o atendimento dessas crianças. $\mathrm{Na}$ sua perspectiva, a Defectología pretendia entender os processos de desenvolvimento humano que estavam comprometidos devido à deficiência e, ao mesmo tempo, propunha soluções para esses problemas. 


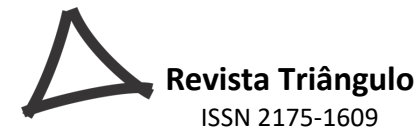

Os estudos de Vygotsky sobre Defectología, realizados a partir do século XX, apresentaram inúmeras reflexões sobre a possibilidade de aprendizagem e de desenvolvimento da pessoa com deficiência, tanto de ordem física como intelectual. Nesse período, qualquer deficiência apresentada por um sujeito era vista como um defeito e, dessa maneira, caracterizava-se como um tipo de inferioridade em relação ao indivíduo. Segundo Kozulin (1994), para compreender o desenvolvimento da criança com deficiência, é necessário, antes de tudo, conhecer e compreender como se dá o processo de aprendizagem num viés da Neuropsicologia.

Vygotsky se preocupava com o nível intelectual da criança e, por isso, procurou desenvolver uma teoria que viesse a estudar o desenvolvimento humano. Por essa razão, Nuernberg (2008, p. 308) afirma que

Sua análise da linguagem no desenvolvimento de surdos e cegos, do processo de formação de conceitos em esquizofrênicos e da reabilitação de afásicos vinha a reboque de uma intenção mais ampla: compreender os aspectos da gênese social do funcionamento psicológico superior.

De acordo com Jannuzzi (2004), na Rússia, após o período da Revolução de 1917, milhares de crianças foram encontradas em condição de vulnerabilidade e dessas, muitas com deficiências causadas pela guerra. O governo soviético, para reparar de certa forma os danos causados às crianças, jovens e adultos, solicitou a colaboração de Vygotsky para a elaboração de propostas educacionais que pudessem vir em auxílio desses indivíduos, amenizando os efeitos do contexto político e social do período.

Em 1925, Vygotsky criou um Laboratório de Psicologia no Instituto de Treinamento de Professores, em Gomel, onde ministrava aulas no curso de Psicologia. O objetivo era atender à demanda das necessidades educacionais das crianças com deficiências, muitas delas mutiladas pela guerra. Esse laboratório surgiu efetivamente em 1929, sendo chamado e conhecido como 'Instituto Experimental de Defectología', onde Vygotsky começou a desenvolver parte de suas pesquisas em relação ao desenvolvimento e à educação da pessoa com deficiência.

Nuernberg (2008) enfatiza que Vygotsky criticava de forma veemente as análises quantitativas da aprendizagem de crianças com deficiência e, com isso, rejeitava qualquer abordagem que quantificava níveis ou graus de incapacidade a partir de comparações com outras crianças sem deficiência, classificando-as em um patamar de normalidade ou anormalidade. De acordo com Skliar (1999, p. 16), "as fronteiras da exclusão aparecem, desaparecem e voltam a aparecer, se multiplicam, se disfarçam e seus limites se ampliam, mudam de cor, de corpo, de nome e de linguagem". Por isso, há uma peculiaridade nos estudos de Vygotsky, segundo os quais é preciso compreender a criança, considerando-a em um todo. $\mathrm{O}$ autor analisa seus aspectos qualitativos para compreender como se organiza o funcionamento psíquico do sujeito em uma perspectiva de diversidade humana.

Para Garcia (2008), a deficiência não pode ser reduzida apenas aos seus componentes biológicos ou às limitações orgânicas, como lesões cerebrais e malformações. Com isso, em seus estudos, Vygotsky separa as deficiências em dois grandes grupos: deficiência primária e deficiência secundária. Na primeira, ele engloba os problemas de ordem orgânica, que não 


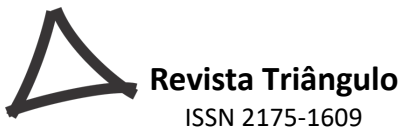

podem ser modificados, enquanto, nas secundárias, inclui aqueles que possuem consequências psicossociais da deficiência, e que podem, em certo modo e/ou período, serem contornados.

Para proporcionar meios de superação da deficiência secundária, Vygotsky aborda a compensação com o objetivo de esclarecer que qualquer meio de compensar a criança não pode ser visto como um processo natural ou biológico, mas sim num processo social. Nesse sentido, Vygotsky (2003, p. 3) faz referência à compensação como "um processo fundamental do desenvolvimento do indivíduo com deficiência”, que se faz presente em qualquer pessoa. A compensação, portanto, está intrinsecamente ligada a um processo substitutivo que garante um desenvolvimento pleno. De acordo com Vygotsky; Luria (1996) apontam a importância de se compreender esses conceitos, pois o limite biológico, a compensação e a supercompensação precisam alcançar um nível específico para haver a formação do talento cultural (VYGOTSKY; LURIA, 1996).

Nessa mesma perspectiva, Góes (1996, p. 3) afirma que, no ser humano, "ocorrem compensações de ordem orgânica, pelas quais um órgão substitui o outro, ou realiza as funções deste, mas, para compreender o funcionamento humano, é essencial considerar as compensações sociopsicológicas”. Isso ocorre porque toda e qualquer relação com o outro surge a partir de um plano sociopsicológico e é nessas trocas, por meio da interação, que se percebem as possibilidades compensadoras, capazes de estabelecer o potencial e promover o desenvolvimento da criança.

Com relação a esse ponto, Bakhtin (2003) defende que a linguagem viva deve ser estudada na relação com o outro e de forma singular. Os estudos bakhtinianos mostram a importância das primeiras relações sociais na representação interior que a criança elabora de si mesma e das coisas a sua volta. Nessa interação é que os saberes vão se construindo, e produzindo sentidos.

Baseado nisso, Góes (1996, p. 3) assevera que todo "o desenvolvimento se constitui, então, com base na qualidade destas vivências, assim, o funcionamento humano vinculado a alguma deficiência depende das condições concretas oferecidas pelo grupo social, que podem ser adequadas ou empobrecidas". Dessa forma, em vários momentos "as consequências sociais do defeito acentuam, alimentam e consolidam o próprio defeito. Neste problema, não existe nenhum aspecto no qual o biológico possa ser separado do social" (Tradução nossa).

Consequentemente, as limitações de ordem secundária são, para Vygotsky, mediadas pela ordem social, diretamente interligadas com o universo cultural, construído e padronizado por uma sociedade em função de um modelo de normalidade, que vem a gerar, por sua vez, na maioria das vezes, barreiras físicas, educacionais e atitudinais que impedem a efetiva participação do sujeito com deficiência nos espaços sociais e culturais comuns aos sujeitos. Com base nessa ideia, Nuernberg (2008, p. 309) enfatiza que

Vygotsky elaborou uma crítica veemente às formas de segregação social e educacional impostas às pessoas com deficiência. Para ele, a restrição do ensino à dimensão concreta dos conceitos é uma estratégia equivocada de organização das práticas educacionais da educação especial. 


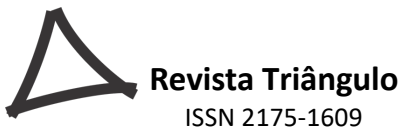

A partir do excerto anterior, pode-se inferir que há concepções equivocadas de profissionais da saúde e da educação sobre a capacidade de aprendizagem das pessoas com deficiência. Com isso, é criado um círculo vicioso em que lhes são negadas as possibilidades e condições de superar as dificuldades nos ambientes sociais e educacionais.

Fica claro, então, que se faz necessário compreender o estudo da Defectología em que Vygotsky registra, a partir do início do século XX, suas reflexões e análises sobre a possibilidade da aprendizagem e desenvolvimento das crianças com deficiência, tanto de natureza física como intelectual.

Kozulin (1994) traz algumas considerações sobre a primeira "Escuela Sanatório" para crianças "anormais", criada por Kaschenko, em 1908, em Moscou, e, ainda, nesse mesmo período, um instituto para a formação de professores em Educação Especial, em San Petersburgo. Conforme o autor, o termo Defectología, nesse período, trazia consigo "conotações técnicas, mas nenhum sentido de preconceito explícito" no que tange à questão da aprendizagem" (KOZULIN, 1994, p. 191).

Toda a proposta de pesquisa e estudos de Vygotsky estão baseados especificamente no potencial da criança e não em seus defeitos (GARCIA, 1999). Com isso, para Vygotsky, a Defectología era vista como "[...] uma esfera de conhecimento teórico e do trabalho científicoprático, e assim, [...] refere-se à criança cujo desenvolvimento se há complicado com o defeito" (VYGOTSKY, 1997, p. 2-3).

No período em que Vygotsky realizou seus estudos nessa área, predominava na sociedade o enfoque terapêutico e clínico da deficiência. As instituições de ensino organizavam suas ações para atender a criança de forma que essa não fosse vista como um sujeito com as mesmas potencialidades e habilidades das demais crianças, mas como alguém limitado a desenvolver diversas atividades e, assim, totalmente inapta para participar efetivamente da sociedade (CARVALHO, 2006). Em vista disso, era negado a elas o direito de desenvolver atividades que as desafiassem e promovessem a sua efetiva aprendizagem.

Carvalho (2006, p. 37) afirma que há o efetivo desenvolvimento da criança quando the são proporcionadas situações em que existam "as mesmas metas educacionais que para os demais, assegurar o acesso efetivo aos bens culturais, mesmo que isso implique a necessidade de uso de recursos especiais, [...] e demande uma ação mais intensiva do outro".

Nesse sentido, Vygotsky afirma que é possível perceber avanços na escola quando ela reconhece que todos são diferentes e procura trabalhar as habilidades das crianças com deficiência. Sassaki (1997, p. 47) afirma que "os problemas da pessoa com necessidades especiais não estão nela tanto quanto estão na sociedade". Ainda em consonância com o excerto anterior, de acordo com Pletsch e Braun (2008, p. 4), a compreensão de Vygotsky aponta que

a criança cujo desenvolvimento foi comprometido por alguma deficiência, não é menos desenvolvida do que as crianças 'normais', porém é uma criança que se desenvolve de outra maneira. Isto é, o desenvolvimento, fruto da síntese entre os aspectos orgânicos, socioculturais e emocionais, manifesta-se de forma peculiar e diferenciada em sua organização sociopsicológica. Assim, não podemos avaliar suas ações e compará-las com as demais pessoas, pois cada pessoa se desenvolve de forma única e singular. 


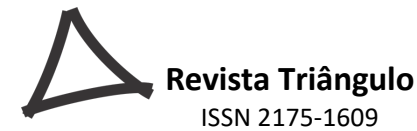

A escola inclusiva que se busca é aquela que possa oferecer um atendimento de qualidade às crianças, sem distinção alguma e que, ao mesmo tempo, não as torne iguais, pois todos têm o direito de serem diferentes. O grande desafio das escolas neste contexto educacional para o atendimento dos alunos, segundo Beyer (2006), é ter um olhar pedagógico que consiga atender os alunos que apresentem uma aprendizagem diferenciada, sem estigmas e preconceitos.

Vygotsky (1997, p. 11-12), ao abordar o tema da Defectología, afirma que:

\begin{abstract}
$\mathrm{Na}$ Defectología, se começou antes a calcular e a medir do que a experimentar, observar, analisar, diferenciar e generalizar, descrever e definir qualitativamente. A Defectología prática também elegeu o caminho mais fácil do número e da medida, e tentou tomar consciência de si como pedagogia menor. Enquanto na teoria o problema se reduzia a um desenvolvimento quantitativamente limitado e de proporções diminuídas, na prática [...] se promoveu a ideia de um ensino reduzido e mais lento.
\end{abstract}

Por isso, Vygotsky (1997, p. 12) reage ao enfoque quantitativo, apresentando a fundamentação da Defectología quando afirma que a "criança cujo desenvolvimento está complicado pelo defeito não é simplesmente uma criança menos desenvolvida que seus coetâneos normais, mas desenvolvida de outro modo". Sustenta, assim, a ideia de que o desenvolvimento da criança com deficiência é o mesmo de outra criança sem deficiência, dita "normal", apenas com algumas limitações que durante o percurso do processo de ensino e de aprendizagem devem ser observadas.

Por outro lado, Vygotsky (1997, p. 14) afirma que "todo defeito cria os estímulos para elaborar uma compensação". É nessa ótica que o autor enfatiza que esse processo compensatório, que é apresentado em seus estudos, constitui-se também em um traço central no estudo do desenvolvimento da criança com deficiência. Para o autor, essa compensação nem sempre poderá ter sucesso, pois é um constante processo de superação e ressignificação.

Acredita-se, aqui, ter-se encontrado o ponto crucial da teoria vygotskyana, enfatizando que as instituições de ensino, por meio da intervenção pedagógica, terão sucesso no processo inclusivo ao se centrarem nos aspectos secundários da deficiência e no desenvolvimento dos processos superiores mais suscetíveis de compensação. O espaço dividido com o coletivo, portanto, é a fonte do desenvolvimento das funções psicológicas das crianças com deficiência.

Os aspectos da deficiência primária provocam algumas limitações na criança, visto que são problemas de ordem orgânica, porém, são as limitações secundárias da mediação social e psicológica que mais interferem no perfil da pessoa com deficiência.

Vygotsky (1997) faz uma crítica ao modelo clínico, que considera a deficiência como um retardo ou atraso mental e não como parte de um processo diferenciado que permite a aprendizagem, desde que os instrumentos e signos utilizados sejam adequados às crianças com deficiência. Sob esse viés, a partir de observações na escola, acredita-se que a forma como o professor ensina é fundamental para os processos de ensino e de aprendizagem. Se os instrumentos pedagógicos utilizados em sala de aula não forem adequados às crianças, elas dificilmente irão se apropriar dos conhecimentos que o professor deseja ensinar.

Com base nos estudos de Vygotsky, pode-se afirmar que esse modelo clínico influenciou fortemente as questões relacionadas às concepções sobre a Educação Especial. Por 


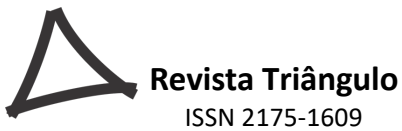

isso, as escolas que possuem uma proposta de Educação Inclusiva e que acreditam no desenvolvimento e no potencial da criança não podem de maneira alguma aproximar-se de concepções que focalizam os limites, as impossibilidades, os "defeitos", e que não visualizam, em momento algum, a possibilidade de superação dessas limitações e de vir a aprender e a se desenvolver de modo mais pleno.

Da mesma forma, autores como López Melero (2005) e Lozano (2002) criticam a questão do diagnóstico clínico que rotula muitos sujeitos que possuem deficiência, apresentando um sujeito "deficitário", sem proporcionar qualquer possibilidade de avanço em nenhuma área (educacional ou socioemocional). Esse diagnóstico clínico é um modo de fragmentar, determinar ou mesmo de classificar os sujeitos quanto à sua necessidade específica ou deficiência. López Melero (2003) enfatiza que todo e qualquer diagnóstico deve ser uma oportunidade para que haja mudança. Assim, o autor destaca que

\footnotetext{
O diagnóstico não pode ser algo perverso. Ao contrário, o diagnóstico é como o umbral do conhecimento, é como uma porta aberta à indagação e à descoberta: é um convite à busca permanente e sempre há de ter um caráter provisório. O desenvolvimento humano não consiste só em assinalar o que alguém é agora, mas o que pode ser com a ajuda educativa dos demais e com a cultura. (LÓPEZ MELERO, 2003, p. 284-285).
}

Diante disso, fica claro que, ao diagnosticar uma deficiência, são necessárias propostas interventivas ou de atividades que sejam possíveis de serem desenvolvidas com crianças com deficiência. Essas atividades devem lhes oferecer as condições necessárias para a aprendizagem e, com isso, possibilitar seu desenvolvimento, superando as suas dificuldades.

Quando Vygotsky (1997, p. 133) apresenta a teoria da criança que supera as dificuldades, ele remete à peculiaridade da superação, pois

\footnotetext{
Desde o ponto de vista dialético, não há concepção mais errônea e incorreta que esta (sobre a associação de causa e efeito), porque precisamente no processo de desenvolvimento, o primário, que aparece na etapa inicial do desenvolvimento é ‘superado' reiteradamente pelas novas formações qualitativas que se originam.
}

Ainda, para o autor, toda criança com ou sem deficiência necessariamente precisa de uma vida social, de um convívio sadio com outras pessoas e, em especial, com seus familiares, bem como de oportunidades de acesso aos signos culturais. Assim, possivelmente encontrem subsídios e construam as suas funções psicológicas superiores, as quais podem trazer meios de se inserir nas práticas sociais dos grupos de que fazem parte (VYGOTSKY, 1997). Sob esse olhar, entende-se que a linguagem tem importante papel no desenvolvimento do ser humano, como se verá a seguir.

\section{Teoria Histórico Cultural: processos inclusivos de aprendizagem da escrita}

Smolka (2012, p. 84) afirma que "o processo inicial de leitura que passa pela escrita, revela fragmentos e momentos do discurso interior, da dialogia interna das crianças, nessa forma de interação verbal. O papel do ‘outro' nessa interação começa a se delinear”. Fica claro 


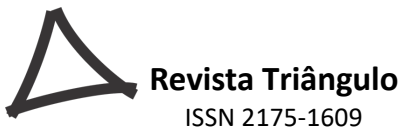

que a apropriação da linguagem escrita pela criança é um processo ou atividade considerada complexa, pois irá provocar em seu desenvolvimento, transformações de ordem psíquica e cultural. Vygotsky (2008a) argumenta que a escrita precisa ter significado para a criança, bem como as atividades relacionadas à escrita e à matemática devem se tornar atividades prazerosas e relevantes e não apenas atividades de repetições ou memorizações. Essas aprendizagens, no seu modo de compreender, deveriam acontecer de uma maneira totalmente natural para serem significativas, da mesma forma como a criança aprende a falar:

O domínio de um tal sistema complexo de signos não pode ser alcançado de maneira puramente mecânica e externa; ao invés disso, esse domínio é o culminar, na criança, de um longo processo de desenvolvimento de funções comportamentais complexas (VYGOTSKY; LURIA; LEONTIEV, 1988, p. 140).

Para Vygotsky (2010), a escrita em uma criança ouvinte é uma linguagem que se constitui em primeiro lugar no seu pensamento para depois ser registrada. Nesse mesmo rumo, Xavier (2002, p. 19) considera que:

\begin{abstract}
A construção da competência do professor para responder com qualidade às necessidades educacionais especiais de seus alunos em uma escola inclusiva, pela mediação da ética, responde à necessidade social e histórica de superação das práticas pedagógicas que discriminam, segregam e excluem, e, ao mesmo tempo, configura, na ação educativa, o vetor de transformação social para a equidade, a solidariedade, a cidadania.
\end{abstract}

Ainda, nessa perspectiva, para Vygotsky (2002, p. 76), deve-se considerar que

\begin{abstract}
As principais fases formais que percorrem a personalidade da criança em sua formação estão diretamente ligadas ao grau de desenvolvimento de seu pensamento, já que, do sistema de cognição em que se realiza toda a experiência interna e externa da criança, dependerá o aparelho psíquico que a divida, analise, conecte e elabore.
\end{abstract}

Pensando nesse processo de aprendizagem da escrita, Vygotsky destaca o desenho e o jogo como pontos de referência que devem estar internalizados para que a criança possa se apropriar efetivamente da linguagem escrita. Ao analisar a pré-história da linguagem escrita, Vygotsky; Luria; Leontiev (1988) ressalta que o gesto, denominado signo visual para a criança, representa o início de tudo: “os gestos são a escrita no ar, e os signos escritos são, frequentemente, simples gestos que foram fixados" (p. 141).

Partindo desse caminho, podem-se citar algumas brincadeiras que o professor, enquanto mediador pode utilizar como metodologia para auxiliar no desenvolvimento da escrita como: o faz-de-conta que ajuda a criança a desenvolver estratégias de simbolização, no qual se utilizam objetos para representar outros; representam-se papéis de outras pessoas etc. Conforme Elkonin (1996) e Leontiev (1998), a atividade do brincar durante a aprendizagem promove na criança diferentes habilidades (sociais, cognitivas, psicomotoras e emocionais) necessárias para o seu desenvolvimento sadio e para a superação de várias dificuldades que encontra durante o seu processo de aprendizagem. De acordo com Vygotsky (2002), o desenvolvimento infantil, 


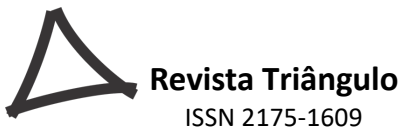

principalmente na idade pré-escolar, tem uma relação intrínseca com o brinquedo, pois propicia uma situação entre o real e o imaginário.

Leontiev (1998) afirma que toda a brincadeira é necessária e é esse processo que permitirá desenvolver os processos psicológicos que auxiliam a criança a se aproximar de um nível maior no seu desenvolvimento e, é através do brinquedo, que a criança estabelece relações com o mundo. $\mathrm{O}$ autor explicita que "não é a imaginação que determina a ação, mas são as condições da ação que tornam necessária a imaginação e dão origem a ela" (LEONTIEV, 1998, p. 127).

Estudos realizados por Luria (1992), sobre o desenvolvimento da escrita, mostram que Vygotsky, em sua trajetória, concluiu que as crianças menores, em especial as que estão em idade pré-escolar, são habilitadas em descobrir a função simbólica da escrita. Já a criança que não passou pela alfabetização inicia esse processo usando a imitação mecânica daquilo que conhece, fazendo, dessa forma, uso da Zona de Desenvolvimento Real, pois apenas faz uso dos seus rabiscos para se expressar. Esses pequenos rabiscos, para Vygotsky, Luria e Leontiev (1988), são representações que a criança domina e o professor poderá usá-los para fazer com que a mesma consiga chegar à Zona de Desenvolvimento Proximal.

De acordo com Vygotsky (2008a), o início do uso da linguagem escrita pelas crianças, mais precisamente pelas crianças menores, é quando essas utilizam os gestos para manifestar sua vontade ou desejos, sem o uso da oralidade. Para o autor,

\footnotetext{
Assim como no brinquedo, também no desenho o significado surge, inicialmente, como um simbolismo de primeira ordem. Como já dissemos, os primeiros desenhos surgem como resultado de gestos manuais [...]; e o gesto, como vimos, constitui a primeira representação do significado. É somente mais tarde que, independentemente, a representação gráfica começa a designar algum objeto. A natureza dessa relação é que aos rabiscos já feitos no papel dá-se um nome apropriado (VYGOTSKY, 2008a, p. 133).
}

Segundo as suas pesquisas, a partir do momento em que a criança inicia os seus rabiscos, iniciam os seus ensaios de desenhos daquilo que sabe que existe. Esse estágio, de acordo com estudos de Vygotsky, Luria e Leontiev (1988), é chamado de Estágio dos Rabiscos, cujo objetivo é "[...] traçar o desenvolvimento dos primeiros sinais do aparecimento de uma relação funcional das linhas e rabiscos na criança, o primeiro uso que ela faz de tais linhas, etc. para expressar significados" (LURIA, 1992, p. 146).

Nesse período inicial, o desenho é uma simples representação de objetos, pois as crianças ainda não conseguem representar palavras. Para que a criança consiga evoluir em seu desenvolvimento, ela precisa "fazer uma descoberta básica - a de que se pode desenhar, além das coisas, também a fala. Foi essa descoberta [...] que levou a humanidade ao brilhante método da escrita por letras e frases; a mesma descoberta conduz as crianças à escrita literal" (VYGOTSKY, 2008b, p. 140).

É perceptível que, para a criança, a escrita é composta de desenhos, ainda sem sentido para os adultos, sem relação com um meio de comunicação, pois "a criança, nesse estágio do desenvolvimento, ainda não se relaciona com a escrita como um instrumento a serviço da memória” (VYGOTSKY; LURIA; LEONTIEV, 1988, p. 156). 


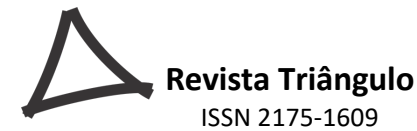

A segunda fase foi denominada de "Estágio da escrita não diferenciada", representada por símbolos, anterior ao ingresso na escola. Esses símbolos são marcas que possuem significados para a criança, pequenos rabiscos utilizados para se lembrar de algo que lhe foi dito, porém, ainda não servem para leitura. Para Vygotsky, Luria e Leontiev (1988, p. 158), esta "é a primeira forma de escrita no sentido próprio da palavra". Desse modo, pode-se afirmar que esses rabiscos representam as futuras escritas que a criança apresentará durante o seu desenvolvimento da escrita.

\footnotetext{
Demos a uma criança de quatro anos e oito meses uma série de palavras: "quadrolivro-menina-locomotiva". A criança anotou cada uma dessas palavras com uma marca, uma depois da outra, a menina "leu": "menina-boneca-cama-caminhão". Vemos que as palavras lembradas pela criança nada têm nada em comum com as palavras dadas; apenas o número das palavras recordadas era o mesmo; seu conteúdo foi inteiramente determinado pelos conjuntos emocionais e interesses da criança (VYGOTSKY; LURIA; LEONTIEV, 1988, p. 159).
}

Nessa citação, é possível observar claramente que a criança usou marcas para as sentenças que lhe foram ditadas. Ela já sabe que há algo escrito, porém, ainda não define o seu significado. Nesse período, a criança precisa de muitos estímulos visuais para o seu desenvolvimento. Para Vygotsky, Luria e Leontiev (1988, p. 155), “a escrita da criança não desempenha ainda uma função mnemónica, como se tornará óbvio se examinarmos as 'sentenças' escritas pela criança após o ditado".

A partir desse momento, conforme os autores, a criança está num processo mais elevado, sabendo diferenciar os rabiscos ou marcas (signos), expressando o conteúdo solicitado. Esse terceiro estágio é representado por uma mistura de símbolos, de letras ou desenhos - é a fase simbólica, em que consegue fazer a diferenciação dos rabiscos (signos primários), passando para fase pictográfica, em que por meio da escrita, a criança faz repetições de letras que já conhece.

Nessa linha de pensamento, para Luria (1988, p. 161), as "linhas e rabiscos são substituídos por figuras e imagens, e estas dão lugar a signos. Nesta sequência de acontecimentos, está todo o caminho do desenvolvimento da escrita, tanto na história da civilização como no desenvolvimento da criança". É nesse período, segundo o autor, que a criança deve saber diferenciar os rabiscos e as marcas por ela descritas no papel. Partindo do exposto, nota-se a importância que o gesto, a brincadeira e o desenho têm para o aprendizado da escrita. Através dessas atividades, é possível desenvolver na criança formas de representação simbólica da realidade. Segundo Vygotsky, Luria e Leontiev (1988), pode-se perceber uma continuidade, uma conexão entre essas atividades, que representam uma preparação para a aquisição da escrita.

Ainda, para os autores Vygotsky, Luria e Leontiev (1988), há ainda outros signos que devem ser estudados: os números e as formas. Sabe-se que, há muitos anos, existem registros sobre a necessidade da criação dos números e quantidades. A criança faz uso da pictografia primitiva para fazer seus registros, usando o desenho para recordar aquilo que vivenciou, desenvolvendo uma atividade intelectual complexa. 

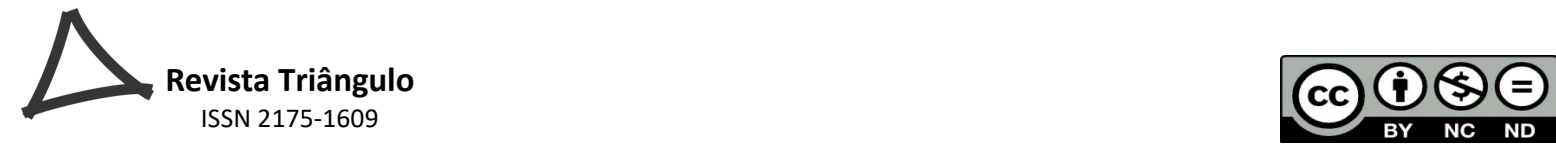

Facilmente se presume que a partir desse processo de pictografia, com o uso da observação e da vontade em dar os primeiros passos rumo à produção da escrita formal, a criança vai conhecendo as letras, formando palavras e dando sentido às suas produções escritas. Vygotsky, Luria e Leontiev (1988) se referem a esse estágio como sendo o domínio exterior da escrita. Neste estágio, a criança conhece letras isoladas, sabe que elas possuem um significado e aprende a fazer as suas marcas: começa, assim, a fazer uma leitura de suas palavras escritas. Com isso, e a partir de um processo lento, porém contínuo, vai aprendendo e conhecendo os sons e a escrita. Os conhecimentos já são transmitidos pela escola de forma organizada, mas a criança ainda não consegue, sozinha, compreender totalmente a complexidade da escrita, pois as suas capacidades de abstração e discriminação ainda não estão desenvolvidas em sua totalidade. Evidencia-se, nesse contexto, mais uma vez, a importância do papel do outro na constituição desse processo, no caso do espaço escolar, ressaltando-se a relevância do professor na mediação da aprendizagem.

Diante disso, percebe-se que a aprendizagem da linguagem implica a ação conjunta de múltiplos processos e fatores. Quando há falha em algum sentido, o caminho para a aprendizagem pode ser dificultado ou interrompido. É fundamental ter em mente que nem todas as crianças e jovens aprendem no mesmo tempo. Sendo assim, um olhar especial, um atendimento específico e o respeito às limitações são condições necessárias para que o processo ensino e aprendizagem possibilite a construção, no aluno, de um sentimento de interesse pelo ambiente escolar.

A aprendizagem é o resultado da estimulação do ambiente sobre o indivíduo que, diante de uma situação-problema, apresenta uma mudança de comportamento em função da experiência (JOSÉ; COELHO, 2000). Desse modo, a escola deve ser o local onde o respeito à diversidade e ao ritmo de cada um seja considerado e avaliado para o (re) planejamento das ações educativas.

Diante disso, é necessário que os professores valorizem cada aluno, levando em consideração a forma como cada um pode aprender, recorrendo a atividades significativas e motivadoras que permitam pensar e construir a aprendizagens.

Assim, percebe-se a importância de um trabalho inclusivo e cuidadoso do professor no processo de construção das aprendizagens dos alunos. A atitude do profissional de ensino e sua relação com a criança é decisivo para que se possa alcançar o sucesso e romper as barreiras das dificuldades. "Ensinar não é transferir conhecimento, mas criar as possibilidades para a sua produção ou a sua construção" (FREIRE, 1996, p. 12). Dessa forma, cabe a todos os profissionais da educação buscar caminhos que levem à construção do saber, todos, de igual forma, têm o direito de aprender.

\section{CONSIDERAÇÕES FINAIS}

Mediante os estudos de Vygotsky, é possível compreender que a interação com o outro é de fundamental importância para o processo de desenvolvimento humano, sobretudo, o de ensino e de aprendizagem. Nessa perspectiva, a linguagem também tem função social, uma vez que é por meio dela que se dá a interação. A criança, em seu processo de constituição, usa a 
linguagem a fim de atender às suas necessidades sociais, de se relacionar socialmente; é por meio da linguagem que a criança interage dialeticamente com o meio, o que resulta no seu desenvolvimento e a torna um sujeito ativo desse contexto.

A partir deste estudo, pôde-se perceber a importância desse processo interativo para construção dos saberes e dos sujeitos. Assim, o ensino e a aprendizagem devem estar pautados em atividades que promovam a ampliação de habilidades funcionais deficitárias ou possibilitem a realização da função desejada e que se encontra impedida por circunstância da deficiência.

Nesse sentido, pensar a aquisição da linguagem escrita por esse caminho da construção dialética de saberes, também, pode se constituir como possibilidade de realizações em favor de uma aprendizagem mais humanística, que propicia a formação do que é essencialmente humano não ser. Considera-se que essa aprendizagem é favorecida quando são apresentados e ensinados às crianças interações ou procedimentos didáticos tomados de sentido e significado, como propõem os estudos de Vygotsky.

Assim, organizar o trabalho pedagógico, tendo como ponto de partida desenhos, brincadeiras e jogos que permitam uma interação com o contexto social, é uma possibilidade de ensino por meio de textos aprimorados, isto em oposição aos procedimentos didáticos que se limitam à decodificação e reprodução de letras e números.

Sabe-se que criar uma sala de aula inclusiva é um grande desafio para o profissional da educação. Porém, é indispensável que haja formações continuadas que preparem e ajudem esses profissionais, dando suporte para que se possam criar ambientes de aprendizagem que valorizem o potencial individual de cada aluno.

Por fim, levando-se em consideração essa perspectiva, percebe-se que o papel da escola é de fundamental importância para que se possam desenvolver atitudes de enfrentamento às limitações por parte dos alunos com deficiências. Tudo o que as crianças querem são oportunidades para poder desenvolver suas habilidades com respeito às diferenças.

\section{REFERÊNCIAS}

BAKHTIN, M. Arte e Responsabilidade. Estética da Criação Verbal. São Paulo: Martins Fontes, 2003.

BARROCO, S. M. S. A educação especial do novo homem soviético e a psicologia de L.S. Vygotsky: implicações e contribuições para a Psicologia e a educação atuais. 2007. Tese (Doutorado) - Araraquara, São Paulo, SP, 2007.

BEYER, H. O. Educação Inclusiva ou Integração Escolar? Implicações pedagógicas dos conceitos como rupturas paradigmáticas. Ensaios Pedagógicos. Brasília: Ministério da Educação e Cultura/MEC/SEESP, 2006.

BRONCKART, Jean-Paul. Atividade de linguagem, textos e discursos: por um interacionismo sócio discursivo. São Paulo: EDUC, 1999.

BRONCKART, Jean-Paul. O agir nos discursos: das concepções teóricas às concepções dos trabalhadores. Campinas: Mercado de Letras, 2008. 
CARVALHO, M. F. Conhecimento e vida na escola: convivendo com as diferenças.

Campinas: Autores Associados, 2006.

ELKONIN, D. B. Epílogo. In: VYGOTSKY, L. S. Obras escogidas: psicología infantil. Trad. Lydia Kuper. Madrid: Visor Dist., 1996, tomo IV, p. 387-412.

FREIRE, Paulo. Pedagogia da autonomia: saberes necessários à prática educativa. São Paulo: Paz e Terra, 1996.

GARCIA, R. M. C. Políticas inclusivas na educação: do global ao local. In: BAPTISTA, C. R.; CAIADO, K. R. M.; JESUS, D. M. (Org.). Educação Especial: diálogo e pluralidade. Porto Alegre: Mediação, 2008.

GARCIA, R. M. C. A educação de sujeitos considerados portadores de deficiência: contribuições vygotskyanas. Ponto de Vista, 1999, v. 1, n 1, p. 4-90.

GÓES, M. C. R. Linguagem, surdez e educação. Campinas, SP: Autores Associados, 1996. JANNUZZI, G. M. A educação do deficiente no Brasil. Campinas, SP: Autores Associados, 2004.

JOSÉ, Elizabete Assunção; COELHO, Maria Tereza. Problemas de Aprendizagem. 12a edição. São Paulo: Ática, 2000.

KOZULIN, A. La psicología de Vygotsky: Biografía de unas ideas. Madrid: Alianza, 1994.

LEONTIEV, A. R. Uma contribuição à teoria do desenvolvimento da psique infantil. In: VYGOTSKY, L.S. et al. Linguagem, desenvolvimento e aprendizagem. São Paulo: Ícone, 1998.

LÓPEZ MELERO, M. Escuelas Inclusivas el Proyecto Roma. Cuadernos de Pedagogía. Barcelona, España, mayo 2005, n 346, p. 53-57.

LOZANO, J. E. A. Prática e estilos de pesquisa na história oral contemporânea. In: AMADO, J.; FERREIRA, M. M. Usos e abusos da história oral. Rio de Janeiro: Ed. FGV, 2002, p. 1525.

LURIA, A. R. A construção da mente. Trad. Marcelo Brandão Cipolla. São Paulo: Ícone, 1992.

NUERNBERG, A. H. Contribuições de Vygotsky para a educação de pessoas com deficiência visual. Psicologia em Estudo. Maringá, PR, abr./jun. 2008, v. 13, n² 2, p. 307 316.

PLETSCH, M. D.; BRAUN, P. A inclusão de pessoas com deficiência mental: um processo em construção. Democratizar. Rio de Janeiro, maio/ago. 2008, v. 2, nº 2, p. 1-12. SASSAKI, R. K. Inclusão: construindo uma sociedade para todos. Rio de Janeiro: WVA, 1997. 
SASSAKI, R. K. Integração e inclusão: do que estamos falando? Temas sobre Desenvolvimento, 1998, v. 7, $\mathrm{n}^{\circ} 39$.

SKLIAR, C. B. A invenção e a exclusão da alteridade "deficiente" a partir dos significados da normalidade. Educação e Realidade. Porto Alegre, jul./dez. 1999, v. 24, n 2.

SMOLKA, A. L. B. A criança na fase inicial da escrita: a alfabetização como processo discursivo. 13. ed. São Paulo: Cortez, 2012.

VYGOTSKY, L. S. Fundamentos da Defectología. Tomo V, 1929.

VYGOTSKY, L. S. Obras escogidas I: problemas teóricos y metodológicos de la psicología. 2. ed. Trad. José Maria Bravo. Madrid: Visor Dist., 1989, 1997, 1997a, tomo I.

VYGOTSKY, L. S. A formação social da mente: o desenvolvimento dos processos psicológicos superiores. 6. ed. São Paulo: Martins Fontes, 2002.

VYGOTSKY, L. S. Psicologia pedagógica. Porto Alegre: Artmed, 2003.

VYGOTSKY, L. S. Pensamento e linguagem. São Paulo: Martins Fontes, 2008a.

VYGOTSKY, L. S. A pré-história da linguagem escrita. A formação social da mente. São Paulo: Martins Fontes, 2008b, p. 122-141.

VYGOTSKY, L. S. Aprendizagem e desenvolvimento na idade escolar. In: VYGOTSKY, L. S.; LURIA, A. R.; LEONTIEV, A. N. (Orgs.). Linguagem, desenvolvimento e aprendizagem. 11. ed. São Paulo: Ícone, 2010, p. 103-116.

VYGOTSKY, L. S; LURIA, A. R. Estudos sobre a história do comportamento: símios, homem primitivo e criança. Porto Alegre: Artes Médicas, 1996.

VYGOTSKY, L. S; LURIA, A. R.; LEONTIEV, A. Linguagem, desenvolvimento e aprendizagem. 5. ed. São Paulo: Ícone, Editora da Universidade de São Paulo, 1988.

XAVIER, A. G. P. Ética, técnica e política: a competência docente na proposta inclusiva. Revista Integração. Brasília, 2002, v. 14, n. 24. 